\begin{tabular}{ll}
\hline & $\begin{array}{l}\text { Kastamonu Eğitim Dergisi } \\
\text { Kastamonu Education Journal }\end{array}$ \\
$\begin{array}{l}\text { Ocak 2019 Cilt:27 Sayı:1 } \\
\text { kefdergi.kastamonu.edu.tr }\end{array}$ & Basvuru Tarihi/Received: 12.12 .2017 \\
& Kabul Tarihi/Accepted: 10.02 .2018 \\
Dol: 10.24106/kefdergi.2464
\end{tabular}

\title{
Eşitsizlikler Konusunun Öğretiminde Problem Kurma Yaklaşımının Akademik Başarıya Etkisi'
}

\section{The Effect of the Problem Posing Approach for Academic Success in the Teaching of Inequalities}

\section{Öz}

\author{
Raşit GÜZEL², Abdullah Çağrı BỉBER ${ }^{3}$
}

Bu araştırmanın genel amacı, problem kurma yaklaşımının öğrencilerin akademik başarısına etkisini incelemektir. Araştırma, 2014-2015 Eğitim Öğretim yılının ikinci döneminde, Kastamonu ili merkez ilçesinde Milli Eğitim Bakanlığı'na bağlı faaliyet gösteren bir devlet okulunun sekizinci sınıfinda öğrenim gören toplam 39 öğrenci ile yürütülmüştür. Çalışma kontrol gruplu yarı deneysel desen modeline göre gerçekleştirilmiştir. Yansız atama ile belirlenen iki sınıftan biri deney grubu ( $n=19)$, diğeri ise kontrol grubu $(n=20)$ olarak seçilmiştir. Araştırmada deney grubunun yer aldığı dersler problem kurma yaklaşımına dayalı planlara göre problem çözme ve kurmayı içeren etkinlikler ile yürütülmüşken, kontrol grubuna ise deney grubundaki problemler çözdürülmüştür. Araştırmada nicel veriler, öğrencilerin akademik başarısını ölçmek için geliştirilen akademik başarı ölçeği kullanılarak toplanmıştır ve gerekli istatistikî teknikler belirlenerek SPSS (Statistical Package for Social Sciences) paket programı yardımı ile analiz edilmiştir. Görüşmelerden elde edilen veriler ise içerik analiz yaklaşımı ile ele alınmıştr. Araştırma sonucunda, araştrrmaya katılan deney ve kontrol grubu öğrencilerinin akademik başarı testinden aldıkları test puanları arasında manidar bir farklılaşma olmadığı belirlenmiştir $[\mathrm{t}(37)=1,963, \mathrm{p}>$.05]. Ancak deney grubunda yer alan öğrenciler problem kurma yaklaşımına dayalı etkinliklere yönelik olumlu görüş bildirmişlerdir.

Anahtar Kelimeler: Matematik öğretimi, problem, problem kurma, akademik başarı

\section{Abstract}

The general aim of this study is to investigate the effect of the problem posing approach for students' academic success. The study was carried out with totally 39 students at two classes in a public school associated with the Ministry of National Education on the central district from Kastamonu province on the second semester of 2014-2015 Educational year. In this study, the experimental pattern of the research is based on pre-test and post-test control group model. One of these two groups formed by an impartial assignment was chosen as experimental group $(n=19)$, the other as control group $(n=20)$. Problem solving and problem posing activities in reference to the activity plans based on the problem posing approach was prepared by the researcher while these activities were practiced on the experimental group, the problems solved in the experimental group were solved in the control group. In the study, the quantitive data obtained through the academic success criteria prepared by the researcher to evaluate the students' academic success. At the same time, semi-structured interview forms were used as a qualitative data collection tool to investigate the ideas of the experimental group students. At the end of the study, the results were analyzed SPSS (Statistical Package for the Social Sciences) and collecting required statistical informations. Descriptive analyses approach was used in order to analyze the data required from the interviews. The results show that there is not a significant difference between the test scores of the experimental and control group students got in the academic success test $[\mathrm{t}(37)=1,963, \mathrm{p}>.05]$. But then experimental group students have expressed positive opinion about the problem posing activities.

Keywords: Teaching mathematics, problem, problem posing, academic success.

1. Birinci yazarın yüksek lisans tezinden üretilmiştir.

2. Milli Eğitim Bakanlı̆̆ı, Kastamonu, Türkiye; https://orcid.org/0000-0001-7635-3951

3. Kastamonu Üniversitesi, Eğitim Fakültesi, Matematik ve Fen Bilgisi Eğitimi Bölümü, Kastamonu, Türkiye; https://orcid.org/0000-0003-0740-6989

Atıf / Citation: Güzel, R., \& Biber, A.Ç. (2019). Eşitsizlikler konusunun öğretiminde problem kurma yaklaşımının akademik başarıya etkisi. Kastamonu Education Journal, 27(1), 199-208. doi:10.24106/kefdergi.2464 


\section{Extended Abstract}

In the mathematics teaching with problem setting approach, it is aimed to determine the students' new problem situations, to form problems by arranging the given mathematical expressions, to provide mathematical real life problems and active participation of the students in the classroom. The main problem addressed in this research is to determine the academic success of the student in a mathematics class in which the activities prepared according to the problem-setting approach are applied and to investigate the effect of the problem-setting approach on this variable.

Problem of research

The problem of the research is the question "What is the impact of the problem-setting approach on academic achievement in teaching the topic of inequalities?".

Sub Problems

1. Is there a significant difference between the post test scores of students in the experimental and control groups participating in the study?

2. Is there a meaningful difference between the retention group scores of the students in the study group and the retention test scores of the control group students?

3. What are the opinions of the students in the study group about the problem-setting activities?

Method

Mixed method was used in this study. In this study, the quasi-experimental research model was used. In the study designed according to the semi-experimental pattern model with control group, two groups are used, one being experimental and the other being control group. Pre- and post-study evaluations are made in experimental and control groups (Büyüköztürk, 2001).

Result

According to the analysis results; There is no difference among the groups that the post-test scores of the experimental group and the control group participating in the survey on "inequalities" are identical or similar. The results of this research were not found to be a result of similar research. However, studies with different findings are available (Mary Ellen Dickerson 1999, Yaman 2003, Aksoy 2004, Akay 2006). In the study conducted by Yaman (2003), it was determined that the students in the control group where the traditional teaching methods were applied and the students in the experimental group in which the probabilistic learning approach was applied, were found to be significantly different from the final test academic achievement scores, and the difference was found to be in favor of the students in the experimental group.

In the retention test 3 weeks after the last test, there was no significant difference between the final test scores and the retention test scores of the students in the experimental group [ $t(18)=2,245, p>.05]$. From this finding, it can be concluded that the teaching methods applied in both experimental and control groups do not have a different effect on the permanence of the students' information and the effects on permanence are similar.

It can be said that mathematics education, which is carried out with the activities of problem-building approach activities as a result of interviews made with the students, affects the interesting and positive aspect of the mathematics lesson. It can be said that mathematics learning is more fun and understandable with the activities applied, the activities have positive effect on the students, and in the following lessons they want different activities besides problem-oriented activities. Parallel to this finding; In Altun (2001) study, it was determined that the fear of mathematics decreased and the sympathies against mathematics were increased in students who were able to establish problems. Turhan (2001) also found a positive relationship between the activities carried out by the problem-solving approach and the willingness of students to learn mathematics to support our findings in the research. However, contrary to these findings, Sahal (2016) has come to the conclusion that the problem-solving approach does not have a significant effect on students' mathematical attitudes. Here, the problem-solving activities were conducted by both students (Silver, 1994; Nixon-Ponder, 1995; Silver, 1997; Nardone and Lee, 2010; Cankoy and Darbaz, 2010; Akay, Soybas and Argun, 2006) ) can be said to have various benefits. 


\section{Giriş}

Son yıllarda matematik eğitimindeki yaklaşım, öğrencilerin doğrudan problemi çözmesini istemek yerine, bilinmeyenleri değiştirerek, yeni veriler ekleyip, soruları değiştirerek problemleri geliştirmek veya özgün soruya bağlı kalarak yeni bir problem yaratmalarını isteme üzerine kurulmaktadır (Akay, 2006). Problem kurma faaliyetlerinde bulunan öğrenciler bilişsel kabiliyetlerine göre ilgi alanlarıyla meydana getirdikleri problemlerle zaman geçirme şansına sahiptirler. İlgi alanları ile uğraşan öğrencilerin matematiğe karşı eğilimlerinde olumlu gelişmeler olması ve bu sayede öğrencilerin kendilerine olan güvenleri, mutluluklarında artşlar meydana gelmesi beklenmektedir (Altun, 2001). Bununla birlikte, problem kurma faaliyetleri problemlerin çözümü için sahip olunan bilgilere işlevsellik kazandırarak yeni bilgiler üretmelerini sağlamaktadır (Cankoy ve Darbaz, 2010). Bundan dolayı, problem kurma yaklaşımının matematik eğitiminde çok önemli bir yeri olduğu ve matematik eğitiminde uygulanan etkinliklerin arasında problem kurma yaklaşımlı etkinliklerin bulunmasının gerekli olduğu düşünülmektedir.

Matematik Ulusal Konseyi (NCTM, 1989) müfredat standartları içinde problem kurmayı "Matematik yapmanın kalbindeki bir aktivite" olarak tanımlamaktadır. Ülkemizde de problem kurma, matematik dersinin önemli bir hedefi olarak kabul edilmektedir. Milli Eğitim Bakanlığı (MEB) tarafindan yayınlanan Matematik Öğretim Programı'nda, ilköğretim okulu matematik dersinin genel hedefleri arasında problem kurabilme yer almaktadır (MEB, 2005). Müfredattaki önemine rağmen problem kurma, matematik eğitimi topluluğundan gereken dikkati toplayamamıştır.

Öğrenciler problem kurma sürecini, Brown ve Walter'in (1983) "olursa ne olur "ve "olmaz ise ne olur" (what-if and what-if-not) stratejisini ve Polya (1957)'nın "geriye bakma" (looking back) adımını uygulayarak başlatabilirler (Brown ve Walter, 1983). Böylece öğrenciler, problem çözme ve problem kurma sürecindeki duyuşsal ve bilişsel süreçleri yaşayarak kullandıkları materyallerin kavramsal anlamlarını geliştirebilirler. Problem kurma, uygun mantıklı bir öğretim stratejisi gibi görünse de hem bilişsel süreçlerin hem de duyuşsal süreçlerin üzerinde problem kurmanın ne şekilde bir etki yarattğı konusunda çok az şey bilinmektedir (Kilpatrick, 1987).

Okullarda matematik öğretiminde, derslerde problem kurma çalışmalarının yapıldığına dair araştırma makaleleri çok yaygın olmamakla birlikte (Bush ve Fiala, 1986; Silver ve Adams, 1987; Axelson, 1992; Friel ve Gannan, 1995; Lopez, 1995; Işık ve Kar, 2012; Kılıç, 2015), daha çok problem kurma yaklaşım teorisinin araştrıldığı makaleler vardır (Moses, Bjork ve Goldenberg, 1990; Brown ve Walter, 1993; Silver, 1994). Ancak problem kurma yaklaşımlarına uygun etkinlikler hazırlayıp matematiğin kendine özel konularının öğretimine dair sınıf seviyelerine uygulanması üzerine kapsamlı araştrrmalar yok denecek kadar azdır (Dillon, 1988). Türkiye'de özellikle ortaokul seviyesindeki öğrenciler üzerinde yapılan çalışmalar neredeyse yoktur. Ayrıca problem kurma yaklaşımı ile özel matematik konularının öğretiminde öğrenci başarısına etkisini araştıran pek az çalışmaya rastlanmıştır. Problem kurma yaklaşımı ile bir matematik dersi yapııırsa ne tür sonuçların ortaya çıkacağı önem arz etmektedir.

\section{Araştırmanın Amacı}

Bu çalışmada ortaokul 8. sınıflarda "Eşitsizlik" konusunun öğretiminde problem kurma yaklaşımının akademik başarıya etkisi araştııımıştır. Eşitsizlikler denklemler gibi açık önermeler olup farklı olarak "=" yerine " $\leq "$, " $<$ ", " >" ve " $\geq$ " gibi sıralama bağıntılarından birini içerdiği söylenebilir (Argün, Arıkan, Bulut ve Halıcıoğlu, 2014). illköğretim matematik öğretim programında eşitsizlik ve denklem konusu 6, 7 ve 8. Sınıflarda sarmal bir şekilde belirli oranlarda yer almış, ancak 5. Sınıf programında eşitsizlik ve denklem konusuna yer verilmemiştir (MEB, 2009). "Denklemler ve Eşitsizlikler" alt öğrenme alanı, toplam 71 kazanım içinde 8 kazanım ile temsil edilmektedir. 8. Sınıfta öğrenim gören öğrencilerden doğrusal denklem sistemlerinin cebirsel olarak çözebilmeleri istenirken, eşitlik ve eşitsizlik arasındaki ilişkiyi açıklayarak birinci dereceden bir bilinmeyenli eşitsizliklerin çözüm kümesini bulmaları ve eşitsizlik grafiklerini çizmeleri beklenmektedir. Matematik öğretimi sürecinde öğrenciler denklem ve eşitsizlikler konuları ile hemen hemen her yıl karşılaşmaktadırlar. Ancak öğrenciler bu kadar yoğun öğrenmelerine rağmen en çok kavram yanılgılarının yaşandığı, hata yapılan konuların başında denklem ve eşitsizlikler gelmektedir (Barnes, 1988; Devlin, 2003; Şandır, Ubuz ve Argün, 2007). Denklemler ve eşitsizlikler konusunda yapılan araştrrmalar (MacGregor ve Stacey, 1997; Üzel, 2007; Yavuz, 2010; Kaplan ve Elif, 2016; Şandır, Ubuz ve Argün, 2007) incelendiğinde, denklemler konusunda yapılan çalışmalar eşitsizlik konusunda yapılan çalışmalara göre nispeten fazla olsa da bu konuların problem kurma yaklaşımı ile öğretilmesi ilgili çalışmalara rastlanılmamıştır.

Problem kurma yaklaşımı ile matematik öğretiminde, öğrencilerin yeni problem durumlarını belirlemeleri, verilen matematiksel ifadeleri düzenleyerek problemler oluşturmaları, matematiksel gerçek yaşam problemleri ile öğrencilerin derse aktif katıımını sağlama gibi amaçlar gözetilmektedir. Bu araştırmada ele alınan esas problem, problem kurma yaklaşımına uygun hazırlanan etkinliklerin uygulandığı bir matematik dersinde öğrencinin akademik başarısını belirle- 
mek ve problem kurma yaklaşımının bu değişken üzerindeki etkisinin ne olabileceğini araştırmaktır.

\section{Araşttrmanın Problemi}

Araştırmanın problem cümlesini "Eşitsizlikler konusunun öğretiminde problem kurma yaklaşımının akademik başarıya etkisi nedir?" sorusu oluşturmaktadır.

\section{Alt Problemler}

1. Araştırmaya katılan deney ve kontrol gruplarındaki öğrencilerin son test puanları arasında anlamlı bir fark var midır?

2. Araştırmaya katılan deney grubu öğrencileri ile kontrol grubu öğrencilerinin kalıcılık testi puanları arasında anlamlı bir fark var mıdır?

3. Araştırmaya katılan deney grubu öğrencilerinin problem kurma etkinlikleri hakkındaki görüşleri nelerdir?

\section{Yöntem}

Yapılan bu araştrrmada karma yöntem (mixed method) kullanılmıştır. Karma yöntemin uygulandığı bu çalışmada, yarı deneysel (quasi-experimental research) araştırma modeli kullanılmıştir. Kontrol gruplu yarı deneysel desen modeline göre tasarlanan araştırmada yansız atama ile oluşturulmuş biri deney diğeri kontrol grubu olmak üzere iki grup kullanılır. Deney ve kontrol gruplarında çalışma öncesi ve çalışma sonrası değerlendirmeler yapılır (Büyüköztürk, 2001).

\section{Araştirma Grubu}

Çalışmada yer alan katılımcılar, 2014-2015 Eğitim Öğretim yılının ikinci dönemi, Kastamonu ili merkez ilçesinde Milli Eğitim Bakanlığı'na bağlı bir devlet okulunun iki tane sekizinci sınıfinda öğrenim gören toplam 39 öğrenciden oluşmaktadır.

\section{Grupların Denkleştirilmesi}

Kontrol ve deney grubunda yer alan öğrencilerin hazır bulunuşluk ve bilgi seviyelerini kıyaslamak amacıyla, 20142015 eğitim-öğretim yılında yapılan birinci Temel Eğitimden Orta Öğretime Geçiş (TEOG) sınavı matematik dersi başarı ortalamaları kullanılmıştır. Ortalamalar arasındaki farklılığın anlamlı olup olmadığını anlamak amacıyla t testi uygulanmıştır. Buna göre her iki grubun TEOG sınavı puan ortalamaları arasında istatistiksel bakımdan anlamlı bir farklılık $[t(37)=0,532, p>.05]$ bulunamamıştr.

\section{Veri Toplama Araçları}

Çalışmada yer alan alt problemlerin analizi için gerekli olan verilerin toplanmasında, araştırmacı tarafindan uzman görüşleri doğrultusunda geliştirilen Akademik Başarı Ölçeği ve deney grubu öğrencilerinin derste yapılan problem kurma etkinlikleri hakkındaki düşüncelerini öğrenmek için yarı yapılandırıımış görüşme formu kullanılmıştır. Akademik başarı ölçeği kontrol ve deney gruplarına uygulama sonunda son-test ve belli bir süre sonra da kalıcılık testi olarak tekrar uygulanmıştr.

\section{Akademik Başarı Ölçeği}

Çalışmada, 8.sınıflarda "Eşitsizlik" konusunun problem kurma yaklaşımı ile öğretiminin akademik başarıya etkisini belirlemek amacıyla, araştırmacı tarafindan, "Eşitsizlik" konusunun öğrenme alanlarıyla ilgili kazanımları dikkate alınarak, geçmiş yıllarda sınavlarda sorulan sorular ve üniteyle ilgili kaynaklar taranarak belirlenen çoktan seçmeli sorulardan faydalanılmıştır.

Tablo 1. Akademik Başarı Testi Kazanım ve Soru Sayıları

\begin{tabular}{|c|c|c|}
\hline Kazanımlar & Soru Numarası & Soru Sayısı \\
\hline $\begin{array}{l}\text { 1-Eşitlik ve eşitsizlik arasındaki ilişkiyi açıklar ve eşitsizlik içeren problemlere uygun mate- } \\
\text { matik cümleleri yazar. }\end{array}$ & $2,5,6,7,17,18,21$ & 7 \\
\hline $\begin{array}{l}\text { 2-Birinci dereceden bir bilinmeyenli eşitsizliklerin çözüm kümesini belirler ve sayı doğru- } \\
\text { sunda gösterir. }\end{array}$ & $1,3,4,12,13,19,20$ & 7 \\
\hline 3-iki bilinmeyenli doğrusal eşitsizliklerin grafiğini çizer. & $\begin{array}{l}8,9,10,11,14,15,16 \\
22,23,24,25\end{array}$ & 11 \\
\hline
\end{tabular}

Akademik Başarı Testi'ni oluşturmak için öncelikle ilgili konuya ait kazanımlar incelenmiştir. Kazanım sayısı ve ders yüküne uygun olarak 40 test maddesi ile deneme testi hazırlanmıştı. Hazırlanan testin geçerlilik ve güvenirliliğini be- 
lirlemek amacıyla matematik eğitimi alanından üç uzmanın görüşü alınmıştır. Uzman görüşleri doğrultusunda bilgi testindeki soru sayısı 30'a düşürülmüştür. Hazırlanan 30 soruluk deneme testinin geçerlilik ve güvenirliliğini belirlenmesi amacıyla ön-test uygulaması, 2013-2014 Eğitim-Öğretim yılının ikinci döneminde Kastamonu ili Merkez ilçesindeki Fen Lisesi ve bir Anadolu Lisesinde bulunan toplam 96 öğrenci üzerinde yapılmıştır.

Uygulama sonuçlarına göre her soru için Madde Güçlük İndeksi ve Madde Ayırıcılık İndeksi hesaplanmıştır. Yapılan madde güçlük ve ayırt edicilik analizlerine göre madde ayırıcılık indeksi -1 ile 0 arasında olan maddelerin testten çıkarılması, indeksi 0 ve 0.30 arası olan maddelerin düzeltilerek, 0.30 'dan yüksek maddelerin ise testte direkt kullanılması (Büyüköztürk, 2001) uygun görülmüştür. Ayırt edicilik indeksi -1 ile 0,3 arasında olan beş madde çıkartılarak 25 sorudan oluşan "Akademik Başarı Testi" hazırlanmıştr. Bu testin KR-20 güvenirlik katsayısı 0.78 olarak hesaplanmıştır.

\section{Görüşme Formu}

Bu çalışmada, deney grubunda yer alan öğrencilerin matematik öğretiminde problem kurma yaklaşımına yönelik görüşleri iki sorudan oluşan bir yarı yapılandırılmış görüşme formu ile alınmıştır. Görüşme formunda yer alan sorular matematik eğitimi alanında 3 uzman akademisyen ve araştırmacılar tarafindan birlikte oluşturulmuştur.

\section{Araştırmanın Uygulama Basamakları}

Araşttrmada deneysel çalışma sürecine geçmeden önce literatür taraması yapılarak kavramsal çerçeve oluşturulduktan sonra, "Eşitsizlikler" konusunda, problem kurma yaklaşımının strateji ve tekniklerine uygun etkinlikler hazırlanmıştır. Çalışmada öğrencilerin akademik başarılarını değerlendirebilmek için geliştirilen Akademik Başarı Ölçeği güvenirlik ve geçerlilik çalışmaları sonrasında veri toplama aracı olarak hazır hale getirilmiştir. Araştırmanın uygulama aşaması aşağıdaki şekilde gerçekleştirilmiştir.

1. Eşitsizlik konusunun öğretimine temel oluşturacağı için hem deney hem de kontrol grubuna "Eşitsizlikler" konusunda araştırma çalışmasından önce gerekli tekrar ve hatırlatmalar yapılmıştır.

2. Deneysel çalışma sürecinde aşağıdaki uygulama basamakları takip edilmiştir:

- Çalışma araştırmacı tarafindan 2014-2015 Eğitim- Öğretim Yılının ikinci döneminde matematik dersinde gerçekleştirilmiştir.

- Deneysel araştırma süreci 11 Mayıs - 26 Mayıs 2015 tarihleri arasında toplam 2 hafta ve haftada 4 er saat olarak 8 saat sürmüştür.

- Bu süreçte, sunum, ön-test ve son-testlerin uygulandığı dersler yer almamıştr.

- 11 Mayıs 2015 tarihinde deney grubu öğrencilerine "Problem Kurma Yaklaşımı" hakkında bilgi sunulmuş ve sürecin temel özellikleri açıklanmıştır.

- Deney ve kontrol gruplarında "Eşitsizlik" konusu araştırmacı tarafindan planlanan şekilde ve ders kitabına bağlı kalınarak uygun yöntem ve tekniklerle işlenmiştir.

- Deney grubu öğrencilerine problem kurma yaklaşımına dayalı, araştırmacı tarafindan hazırlanan etkinlik planlarına göre problem çözme ve kurmayı içeren etkinlikler uygulanırken, kontrol grubuna ise deney grubuna çözdürülen problemler çözdürülmüştür.

- Deney grubu öğrencilerinin araştırma süresince kendi aralarında etkileşimlerine olanak sağlanıp, süreç içinde kazanımların değerlendirilmesi için etkinlik kâğıtları gözden geçirilmiş, öğrenciler cevapları ile ilgili dönütler verilmiş, gerekli yerlerde rehberlik yapılmıştır.

- Araştrrma süreci sonunda 26 Mayıs 2015 tarihinde son-test olarak her iki gruba da, araştrrmacı tarafindan geliştirilen ve "Eşitsizlik" konusunu içeren Akademik Başarı Ölçeği uygulanmıştır. Ölçeklerden elde edilen veriler SPSS (Statistical Package for Social Sciences) paket programına girilerek ve gerekli istatistikî teknikler belirlenerek analizler yapılmıştir.

- Son test uygulandıktan 3 hafta sonra da aynı test tekrar uygulanarak öğrenmelerin kalıcılığı incelenmiştir.

\section{Verilerin Analizi}

Araştırmanın amaçları ve problemleri doğrultusunda toplanan nicel veriler, verilerin özelliklerine uygun istatistiksel analiz teknikleri kullanılarak bilgisayar ortamında SPSS-22 (Statistical Package for the Social Sciences) paket programı ile çözümlenmiş, elde edilen bulgular tablo ve grafikler halinde sunulmuştur. Bu doğrultuda araştırmanın her bir alt problemi için uygun aritmetik ortalama, yüzde, frekans ile bağımsız grupların başarılarının karşılaştırılmasında 0,05 anlamlıık düzeyinde t-testleri kullanılmıştır.

Ayrıca, görüşmelerden elde edilen veriler içerik analiz yaklaşımı ile ele alınmıştır. Katlımcı öğrencilerin cevap kâğıt- 
larından oluşan nitel veriler içerik analizi yapılarak çözümlenmiş olup, üç uzman tarafindan değerlendirilmiş ve \%90 uyumluluk yüzdesi tespit edilmiştir. Katılımcılar ile yapılan yüz yüze görüşmeler neticesinde elde edilen veriler katılımcıların sıra numarasına göre kodlanmış, öğrencilerin isimleri yerine D1, D2, D3...biçiminde kodlar kullanılarak araştırma verileri set halinde düzenlenmiştir. Ulaşılan sonuç kategorileri için ifade edilme sıklığı (frekans) ve ifade edilme yüzdeleri hesaplanmıştır. Bir öğrencinin cevabı birden fazla kategoriye girebildiği için frekans toplamı örneklem büyüklüğünden daha büyük olabilmektedir. Ifade edilme yüzdesi ise o kategorideki ifade sayısının toplam ifade sayısına oranı olarak hesaplanmıştır.

\section{Bulgular}

Bu bölümde, çalışmanın amacına uygun araştırma sorularının çözümü için belirlenen ölçme araçlarının uygulanmasıyla elde edilen veriler istatistiksel tekniklerle analiz edilmiş, elde edilen bulgular alt problemler dikkate alınarak tablolaştırılmış ve analiz sonuçlarına dayalı yorumlara yer verilmiştir.

Tablo 2. Deney ve Kontrol Gruplarının Son Test ve Kalıcılık Testi Puanlarına İlişkin Normal Dağılım Analizi İçin Shapiro-Wilk Testi

\begin{tabular}{lcc}
\hline Grup/Test & Shapiro-Wilk & Çarpıklık Katsayısı \\
\hline Deney Son-test & $0,973(>.05)$ & 0,215 \\
Deney Kalıcılık testi & $0,974(>.05)$ & 0,203 \\
Kontrol Son-test & $0,958(>.05)$ & 0,583 \\
Kontrol kalıcılık testi & $0,967(>.05)$ & $-0,522$ \\
\hline
\end{tabular}

Tablo 2'ye göre, deney grubunun son test $(0,973)$ ve kalıcılık testi $(0,974)$ Shapiro-Wilk katsayıları ve kontrol grubunun son test $(0,958)$ ve kalıcılık testi $(0,967)$ Shapiro-Wilk katsayıları 0.05 ten büyük olduğu için gruplar normal dağılım göstermektedir. Ayrıca, kontrol grubunun son test $(0,583)$ ve kalıcılık testi $(-0,522)$ çarpıklık katsayıları \pm 1.96 arasında olduğundan dolayı grupların normal dağılım gösterdikleri bu analizlerle de desteklenmiştir. Gruplar normal dağılım gösterdiği için, verilerin analizinde parametrik testler olan bağımlı gruplar ve bağımsız gruplar t-testi uygulanmıştır.

\section{Birinci Alt Probleme İlişkin Bulgu ve Yorumlar}

Araştırmanın birinci alt problemi kapsamında "Araştırmaya katılan deney ve kontrol gruplarındaki öğrencilerin son test puanları arasında anlamlı bir fark var mıdır? " sorusuna cevap aranmıştır. Bu bağlamda ilgili alt problemi değerlendirmek için deney ve kontrol grubundaki öğrencilere uygulanan son-testten elde edilen puanları için t-testi analizi yapılmıştır. Bulgular Tablo 3’de verilmiştir.

Tablo 3. Deney ve Kontrol Grubunun Son-test Puanlarına Iilişkin t-Testi

\begin{tabular}{lcccccc}
\hline Grup & $\mathrm{N}$ & $\bar{X}$ & $\mathrm{SS}$ & $\mathrm{sd}$ & $\mathrm{t}$ & $\mathrm{p}$ \\
\hline Deney Sontest & 19 & 15,11 & 26,63 & 37 & 1,963 &, 057 \\
Kontrol Sontest & 20 & 12,35 & 25,21 & & & \\
\hline
\end{tabular}

Analiz sonuçları, araştırmaya katılan deney ve kontrol grubu öğrencilerinin akademik başarı testinden aldıkları sontest puanları arasında manidar bir farklılaşma olmadığını göstermektedir $[t(37)=1,963, p>.05]$. Bu bulgu, araştırmaya katilan deney grubu $(\bar{X}=15,11)$ ve kontrol grubunun $(\bar{X}=12,35)$ son-test puanları arasında istatistiksel olarak bir fark olmadığını göstermektedir.

\section{íkinci Alt Probleme İlişkin Bulgu ve Yorumlar}

Araştırmanın ikinci alt problemi olan "Araştırmaya katılan deney grubu öğrencileri ile kontrol grubu öğrencilerinin kalıcılık testi puanları arasında anlamlı bir fark var mıdır?" sorusunu yanıtlama amacıyla kalıcılık puanlarına yönelik t-testi yapılmıştır. Bulgular Tablo 4'te verilmiştir.

Tablo 4. Deney ve Kontrol Grubunun Kalıcılık Puanlarına ilişkin t-Testi

\begin{tabular}{llllccc}
\hline Grup & N & $\bar{X}$ & SS & sd & t & p \\
\hline Deney Kalıcılık & 19 & 13,26 & 20,12 & \multirow{2}{*}{37} & 0,158 & \multirow{2}{*}{875} \\
Kontrol Kalıcılık & 20 & 13,05 & 18,91 & & & \\
\hline
\end{tabular}

Tablo 4'e göre, araştırmaya katılan deney $(\bar{X}=13,26)$ ve kontrol $(\bar{X}=13,05)$ grubu öğrencilerinin akademik başarı testinden aldıkları kalıcılık puanları arasında manidar bir farklılaşma olmadığı görülmektedir [t(37)=0,158, p>.05]. Bir

| Kastamonu Eğitim Dergisi, 27(1), 2019| 
başka ifadeyle, etkisi test edilen programa dâhil olan deney grubu ile normal öğretime devam edilen kontrol grubu arasında bir farklılaşma olmadığı ortaya konmuştur.

\section{Üçüncü Alt Probleme ilişkin Bulgu ve Yorumlar}

Araştırmanın üçüncü alt problemi olan "Araştırmaya kațlan deney grubu öğrencilerinin problem kurma etkinlikleri hakkındaki görüşleri nelerdir? " sorusunu yanıtlama amacı ile deney grubunda yer alan öğrencilerle gerçekleştirilen yarı yapılandırılmış görüşmelerden elde edilen bulgular aşağıda tablolarda sunulmuştur. Öğrencilerin görüşlerinin okuyucu tarafindan daha iyi anlaşılabilmesi için bu bölümde doğrudan alıntılara da yer verilmiştir. Bu kapsamda Matematiğe Yönelik Öğrenci Görüşme Formunda yer alan ilk soru olan "Matematik dersinde yürütülen problem kurma etkinlikleri ile ilgili düşüncelerin nelerdir?" sorusuna öğrencilerin verdikleri cevaplar Tablo 5.'da sunulmuştur.

\section{Tablo 5. Öğrencilerin Problem Kurma Etkinlikleri Hakkındaki Görüşleri}

\begin{tabular}{|c|c|c|c|}
\hline Tema & Nedenleri & $f$ & $\%$ \\
\hline \multirow{3}{*}{$\begin{array}{l}\text { Olumlu } \\
\text { Düşünenler }\end{array}$} & Etkinlikler Eğlenceliydi & 6 & 33 \\
\hline & Anlamayı Kolaylaşttrdı & 5 & 28 \\
\hline & Kalıcı Öğrenme Gerçekleşti & 2 & 11 \\
\hline \multirow{2}{*}{$\begin{array}{l}\text { Olumsuz } \\
\text { Düşünenler }\end{array}$} & Problem Kurmak Zordu & 3 & 17 \\
\hline & Etkinlikler Anlaşılmadı & 2 & 11 \\
\hline
\end{tabular}

Tablo 5.'da görüldüğü gibi, problem kurma etkinlikleri hakkında öğrencilerin toplam \%72'si olumlu düşünürken, \%28'i etkinlikler hakkında olumsuz fikir beyan etmiştir. Öğrencilerin \%17'si olumsuz düşünmelerine sebep olarak problem kurma etkinliklerinin zor olmasını göstermiştir. Görüşleri alınan öğrencilerin \%33’ü etkinliklerin eğlenceli olduğunu, toplamda \%28'lik bir kesim ise problem kurma etkinliklerinin konuyu daha iyi anlamalarına katkı sağlamadığını düşündüklerini ifade etmişlerdir. Bulgulardan yola çıkarak, problem kurma yaklaşımlı etkinliklerin öğrenciler üzerinde genel anlamda olumlu bir etki yarattğı söylenebilir.

Problem kurma etkinlikleri ile ilgili görüşü sorulan D5 "Problem kurma etkinliği sayesinde yeni bir şeyler üreterek dersin içinde olmamı sağladı. Normal ders anlatımına göre daha rahat anladım ve gerçekçi oldu." şeklinde cevap vermiştir.

Öğrenci D8 ise "Bence olumlu düşünüyorum. Dersimiz bu şekilde daha eğlenceli ve hareketli geçiyor. Motivasyonum biraz daha artt. Eskiye göre daha iyi anladığımı düşünüyorum." demektedir.

Matematiği sevmesinin nedenleri arasında problem kurmayı belirten D1 "Ben problem kurmayı sevdim. Kendi problemimi kendim kurup kendim çözmem hoşuma gitti. Bu etkinliklerle öğrendiklerimi hiç unutmayacağımı düşünüyorum." demektedir.

D7 ise "Aslında hoşuma gitti. Tahtaya kalkıp soru çözmek bana zor geliyordu. Şimdi yaptı̆ı̆ız bu etkinlikler sayesinde öğrendiklerimi daha rahat ortaya koymayı elde ettim." cevabını vermiştir.

D6 "Bana kalırsa bu etkinlikler konuyu daha iyi kavramamızı sağlıyor. Karşımıza çıkabilecek sorulara dair daha fazla bilgi sahibi olmamıza katkıda bulunuyor. Aynı zamanda ders olduğundan daha keyifli bir şeklide ilerliyor." demektedir. Bunun yanında D3 “Bu etkinlikler zor geldiği için yapamadım." demiştir.

Matematiğe Yönelik Öğrenci Görüşme Formunda ikinci sırada yer alan "Matematik dersinde farklı bir etkinlikler yapmak ister misin?" sorusuna öğrencilerin verdikleri cevaplar Tablo 6.'de sunulmuştur.

Tablo 6. Farklı Etkinlik İsteği İle ilgili Görüşleri

\begin{tabular}{llcc}
\hline Tema & & $f$ & $\%$ \\
\hline \multirow{2}{*}{ Farklı Etkinlik Yapma İsteği } & Farklı Etkinlik İsteyen & 10 & 50 \\
& Farklı Etkinlik İstemeyen & 10 & 50 \\
\hline \multirow{3}{*}{ Önerilen } & Eğitsel Oyun & 4 & 24 \\
Etkinlikler & Yarışma & 2 & 12 \\
& Çalışma Kağıtları ve Test & 4 & 24 \\
& Araştırma Soruları & 2 & 12 \\
& Problem Kurma Etkinlikleri & 5 & 28 \\
\hline
\end{tabular}


Tablo 6. da görüldüğü gibi, uygulama sonrasında öğrencilerin yarısı (\%50) matematik derslerinde problem çözme etkinliklerinden farklı etkinlik yapmak isterken, diğer yarısı ise problem çözme uygulamalarının yeterli olduğunu belirtmişlerdir. Ayrıca görüşmelerde, öğrencilerin \%28'i problem kurma etkinliğini önermişlerdir. Bu bulgulardan anlaşılacağı gibi öğrencilerin matematik öğretim etkinlikleri arasında problem kurmanın da yer alması gerektiğini düşündükleri söylenebilir.

Uygulama sonrasında yapılan görüşmelerde farklı etkinlik isteği ile ilgili görüşleri sorulan öğrencilerden önerilen etkinlikler arasında problem kurma etkinliğini söyleyen D17 "Hayır farklı bir etkinlik yapmak istemiyorum. Çünkü bu problem kurma etkinliği oldukça güzel oldu." cevabını vermiştir.

D9 “Evet isterim. Konuyu en kolay anlatan oyun şeklinde olan bir etkinlik yapmak isterim." demektedir.

Farklı bir etkinlik öneren D13 ise "Evet isterim. Mesela her hafta yarışmalar yapalım. Yarışmada birinci olan birinciliğini bozmak istemez, diğerleri de birinciyi geçmek için hırslanıp daha çok çalışılar ve bütün öğrencilerin başarısı artar." demiştir.

D6 ise "Bence zaten matematik dersi güzel geçiyor. Tahtaya kalkıp soru çözüyoruz. Çözdügümüz testler ile çok eğlenceli geçiyor ve matematiği de çok iyi anlıyorum." demektedir.

\section{Sonuç ve Öneriler}

Bu çalışmada, "Eşitsizlikler" konusunun öğretiminde kullanılan problem kurma çalışmalarının öğrencilerin akademik başarılarına ve öğrenmenin kalıcılığına olan etkisi araştırılmıştır.

Analiz sonuçlarına göre; "Eşitsizlikler" konusunda araştırmaya katılan deney grubu ve kontrol grubunun son-test puanlarının birbirine denk veya benzer özellikte olduğu, gruplar arasında bir farklılaşma olmadığı görülmektedir. Yapılan bu araştırma sonuçlarına benzer bir araştırma sonucuna rastlanmamıştı. Ancak bu bulgunun aksine; yurt içi ve yurt dışı çeşitli çalışmalar mevcuttur (Mary Ellen Dickerson 1999; Yaman, 2003; Aksoy, 2004; Akay, 2006). Yaman (2003) tarafindan yapılan çalışmada geleneksel öğretim yöntemlerinin uygulandığı kontrol grubundaki öğrenciler ile probleme dayalı öğrenme yaklaşımının uygulandığı deney grubundaki öğrencilerin son test akademik başarı puanları arasında anlamlı düzeyde farklııık meydana geldiği belirlenmiş ve farklıığın deney grubundaki öğrencilerin lehine olduğu bulunmuştur.

Son testin uygulandığı tarihten 3 hafta sonra yapılan kalıcılık testinde araştırmaya katılan problem kurma yaklaşımı ile öğretim yapılan deney grubu öğrencilerinin akademik başarı testinden aldıkları son test puanları ile kalıcılık testi puanları arasında anlamlı bir farklılaşma görülmemiştir $[t(18)=2,245, p>.05]$. Bu bulgudan hareketle hem deney hem de kontrol grubunda uygulanan öğretim yöntemlerinin öğrencilerin bilgilerinin kalıcılıklarını üzerinde farklı etki göstermedikleri, kalıcılık üzerindeki etkilerinin denk, benzer olduğu sonucuna varılabilir. Ayrıca araştırmada deney grubu öğrencilerinin kalıcııık testinden aldıkları puanla, kontrol grubundaki öğrencilerin kalıcılık testinden aldıkları puanlar arasında manidar bir farklılaşma da görülmemiştir. Buna göre, deney grubunda ele alınan problem kurma yaklaşımlı model, kontrol grubunda ders kitabına bağlı kalınarak kullanılan uygun yönteme kıyasla öğrenmenin kalıcılığına olan etkisi bakımından anlamlı bir farklılık oluşturmadığı söylenebilir.

Öğrencilerle yapılan görüşmeler neticesinde problem kurma yaklaşımı etkinlikleri ile gerçekleştirilen matematik öğretiminin, matematik dersine duyulan ilgiyi olumlu yönde etkilediği söylenebilir. Uygulanan etkinliklerle matematik öğrenmenin daha eğlenceli ve anlaşılır olduğu, etkinliklerin öğrenciler üzerinde pozitif yönde etki yarattğı ve daha sonraki derslerde de problem kurma yaklaşımlı etkinliklerin yanında farklı etkinlik istedikleri söylenebilir. Bu bulguya paralel olarak; Altun (2001) çalışmasında problem kurmayı başarabilen öğrencilerde matematiğe karşı duyulan korkunun azaldığını ve matematiğe karşı sempatilerinin arttğını belirlemiştir. Turhan (2001) da araştirmasında bulgularımızı destekler şekilde problem kurma yaklaşımı ile yürütülen etkinliklerle öğrencilerin matematik öğrenmeye karşı isteklilikleri arasında pozitif bir ilişki bulmuştur. Ancak bu bulguların aksine; Şahal (2016) problem kurma yaklaşımının öğrencilerin matematik tutumları üzerinde kayda değer bir etkisinin olmadığı sonucuna ulaşmıştır. Buradan, problem kurma etkinliklerinin hem öğrencilere (Silver, 1994; Nixon-Ponder, 1995; Silver, 1997; Nardone ve Lee, 2010; Cankoy ve Darbaz, 2010; Akay, Soybaş ve Argün, 2006), hem de öğretmenlere (Lin, 2004) çeşitli yararları bulunduğu söyleyenebilir.

\section{Öneriler}

Problem kurma yaklaşımı ile gerçekleştirilen bu çalışmanın farklı etkilerini görebilmek adına farklı sınıf düzeylerinde ve daha uzun süreli uygulanıp öğrencilerin akademik başarılarına etkileri araştırılması önerilebilir.

Yapılan bu çalışmada, problem kurma yaklaşımının öğrencilerin matematiğe yönelik görüşlerini olumlu yönde etkile- 
diği görülmüştür. Bu nedenle, öğrenme - öğretme süreçlerinde matematik öğretmenlerine problem kurma yaklaşımına yer vermeleri önerilmektedir.

Milli Eğitim Bakanlığı tarafindan öğretmenlerde farkındalık yaratılması amacıyla Problem kurma becerisini kazandırmaya yönelik olarak bu konu kapsamında öğretmenlere hizmet içi eğitim verilebilir.

Öğrencilere rutin ve klasik sözel problemlerin haricinde, günlük yaşamla ilgili, eksik verili ya da açık-uçlu matematiksel durumlar sunularak, öğretmenler öğrencilerini yeni problemler üretmeye teşvik etmeli.

\section{Kaynakça}

Akay, H. (2006). Problem kurma yaklaşımı ile yapılan matematik öğretiminin öğrencilerin akademik başarısı, problem çözme becerisi ve yaratıclığı üzerindeki etkisinin incelenmesi. Unpublished doctoral dissertation, Gazi Üniversitesi Eğitim Bilimleri Enstitüsü, Ankara.

Akay, H., ve Soybas, D. ve Argün, Z.(2006). Problem Kurma Deneyimleri ve Matematik Öğretiminde Açık-Uçlu Soruların Kullanımı. Kastamonu Eğitim Dergisi, 14 (1), 129-146.

Aksoy, B. (2004). Coğrafya öğretiminde Probleme Dayalı Öğrenme Yaklaşımı. Yayınlanmamış Doktora Tezi, Gazi Üniversitesi Fen Bilimleri Enstitüsü. Ankara.

Altun, M. (2001). "Matematik Öğretimi". Bursa: Erkam Matbaası.

Argün, Z., Arıkan, A., Bulut, S., Halıcıoğlu, S. (2014). Temel Matematik Kavramların Künyesi. Ankara: Gazi Kitabevi

Axelson, S. L. (1992). Supermarket challenge. Aritmetic Teacher, 40, 84-88

Barnes, M. (1988). Understanding The Function Concept: Some Result of Interviews with Secondary and Tertiary Students, Research on Mathematics Education in Australia, 24-33.

Brown, S. I., ve Walter, M. I. (1993). Proplem posing: reflection and aplications. Hillsdale, NJ:Erlbaum.

Brown, S. I., ve Walter, M. I. (1983). The art of problem posing. Hillsdale, NJ: L. Erlbaum Associates.

Bush. W.S., ve Fiala. A. (1986). Problems stories: A new tvist on problem posing. Arithmetic Teacher, 34(4), 6-9.

Büyüköztürk, Ş. (2001). Deneysel Desenler, Öntest-Sontest, Kontrol Grubu Desen ve Veri Analizi, Ankara: Pegema Yayınclık

Cankoy, O. ve Darbaz, S. (2010). Problem kurma temelli problem çözme öğretiminin problemi anlama başarısına etkisi. Hacettepe Üniversitesi Eğitim Fakültesi Dergisi, 38, 11- 24.

Devlin, K. (2003). The Forgotten Revolution, http://www.maa.org/devlin/devlin_03_03.html, Erişim tarihi: 08.04.2012.

Dillon, J. T. (1988). Levels of problem finding vs. problem solving. Questioning Exchange, 2(2), 105-115.

Friel, J. O.,ve Gannan, G. E.(1995). What if...? A case in point. Mathematics Teacher, 88, 320-322.

Işık, C. ve Kar, T. (2012). ilköğretim matematik öğretmeni adaylarının kesirlerde bölmeye yönelik kurdukları problemlerde hata analizi. Kuram ve Uygulamada Eğitim Bilimleri, 12(3), 2289-2309.

Kaplan, A., ve Elif, A. Ç. I. L. (2016). Ortaokul 4. Sınıf Öğrencilerinin Eşitsizlik Konusundaki Bilgi Oluşturma Süreçlerinin Incelenmesi. Bayburt Eğitim Fakültesi Dergisi, 10(1), 130-153.

Kilic, C. (2015). Analyzing Pre-Service Primary Teachers' Fraction Knowledge Structures through Problem Posing. Eurasia Journal of Mathematics, Science \& Technology Education, 11(6).

Kilpatrick, J. (1987). Problem formulating:Where do good problems come from? In A.H.Schoenfeld(Ed.), Cognitive science and mathematics education (pp.123-147). Hillsdale, NJ: Erlbaum.

Lin, P. J. (2004). Supporting Teachers on Designing Problem-Posing Tasks as a Tool of Assessment to Understand Students' Mathematical Learning. International Group for the Psychology of Mathematics Education.

Lopez, R.F. (1995). Generating real-life problems fort he classroom. Teaching Mathematics and its Applications, 14(4), 156-162.

Macgregor, M. \& Stacey, K. (1997). Students' Understanding of Algebraic Notation: 11-15, Educational Studies in Mathematics, 33, 1-19.

Mary Ellen Dickerson, O. (1999). "The Relationsships of Cognitive Learrning Steyles, Mathematics Attitude, and Achievement in a problemposing Classroom", Unpuplished Ph. D Dissertation, The Universty of Tennesse, United States.

MEB. (2005). “ilköğretim Matematik Dersi Öğretim Programı ve Kılavuzu (1-5. Sınıflar)”, MEB Devlet Kitapları Müdürlüğü, Ankara

MEB. (2009). Illköğretim matematik dersi öğretim programı ve kılavuzu. (6-8. Sınıflar)”, MEB Devlet Kitapları Müdürlüğü, Ankara

Moses, B.M., Bjork, E., ve Goldenberg, E.P. (1990). Beyond problem solving: Problem posing. InT. J. Cooney (Ed.), Teaching and learning mathematics in the 1990's (pp. 82-91). Reston, VA: National Counsil of Teachers of Mathematics.

Nardone, C. F., ve Lee, R. G. (2010). Critical inquiry across the disciplines: Strategies for student-generated problem posing. College Teaching, 59(1), 13-22.

Nctm (1989). Curriculum and evaluation standards for school mathematics, Reston: National Counsil of Teachers of Mathematics.VA

Nixon-Ponder, S. (1995). Using Problem-Posing Dialogue: In Adult Literacy Education. Adult learning, 7(2), 10-12.

Polya, G. (1957). How to solve it. A new aspect of mathematical method. Princeton, NJ: Princeton

| Kastamonu Eğitim Dergisi, 27(1), 2019 | 
Sılver, E. A., Adams, V .M. (1987). Using open-ended problems. Aritmetic teacher,34(May), 34-35

Silver, E. A. (1994). On mathematical problem posing. For the Learning of Mathematics, 14 (1), 19-28

Silver, E. A. (1997). Fostering creativity through instruction rich in mathematical problem solving and problem posing. Zdm, 29(3), 75-80.

Şahal, M. (2016). Problem Kurma Yaklaşımı ile İşlenen Tam Sayılar Konusunun Öğrencilerin Akademik Başarısına ve Matematik Tutumlarına Etkisi. Yüksek Lisans Tezi. Marmara Üniversitesi, Fen Bilimleri Enstitüsü İstanbul.

Şandır, H., Ubuz, B. ve Argün, Z. (2007). 9. sınıf öğrencilerinin aritmetik işlemler, sıralama, denklem ve eşitsizlik çözümlerindeki hataları. Hacettepe Üniversitesi Eğitim Fakültesi Dergisi, 32, 274-281.

Turhan, B. (2011). “Problem kurma yaklaşımı ile gerçekleştirilen matematik öğretiminin ilköğretim 6. sınıf öğrencilerinin problem çözme başarıları, problem kurma becerileri ve matematiğe yönelik görüşlerine etkisinin incelenmesi.” Yüksek Lisans Tezi, Anadolu Üniversitesi Eğitim Bilimleri Enstitüsü, Eskişehir

Üzel, D. (2007). Gerçekçi matematik eğitimi (RME) destekli eğitimin ilköğretim 7. Sınıf matematik öğretiminde öğrenci başarısına etkisi.

Yaman, S. (2003) Fen Bilgisi Eğitiminde Probleme Dayalı Öğrenmenin Öğrenme Ürünlerine Etkisi. Yayınlanmamış Doktora Tezi Ankara: Gazi Üniversitesi.

Yavuz, B. (2010). Ar-Ge Faaliyetlerine İlişkin Teşvikler ve Ar-Ge Giderlerinin Ums-Tms Kapsamında Mali Tablolara Yansıtılması. Yayımlanmamış Yüksek Lisans Tezi, Marmara Üniversitesi Sosyal Bilimler Enstitüsü, İstanbul. 